\title{
Regional Features in Evaluating Nutrition and Health Conditions of Children and Adolescents
}

\author{
Dariya Doskabulova ${ }^{1}$, Arstan Mamyrbaev $^{1 *}$, Artashes Tadevosyan ${ }^{2}$, Perizat Aitmaganbet $^{1}$, Nurgul Alekenova ${ }^{3}$ \\ ${ }^{1}$ Department of Hygienic Disciplines with Occupational Diseases, West Kazakhstan Marat Ospanov Medical University, Aktobe, \\ Kazakhstan, Asia; ${ }^{2}$ Department of Public Health and Health Organization, Yerevan State Medical University after Mkhitar \\ Heratsi, Yerevan, Armenia, Asia; ${ }^{3}$ Department of Academic Work, West Kazakhstan Marat Ospanov Medical University, Aktobe, \\ Kazakhstan, Asia
}

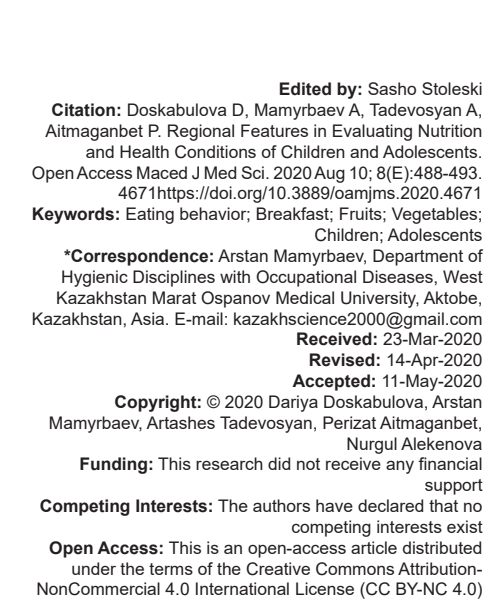

\begin{abstract}
BACKGROUND: The frequency of breakfast consumption as a determinant of fruit and vegetable intake among children and adolescents has been poorly investigated.

AIM: In this article, we examine whether irregular food intake is associated with fruit and vegetable intake among children and adolescents.

METHODS: We use a separate analysis, with special attention being paid to the potentially changing effects of gender and age. The methodology of health behavior in school-aged children is used.

RESULTS: The obtained results show that irregular breakfast consumption among children and adolescents is associated with a low frequency of fruit and vegetable intake and that gender and age can play a decisive role. Various associations observed in different age and gender groups indicate the importance of a separate analysis of fruit and vegetable intake and types of food.

CONCLUSION: The results emphasize the importance of encouraging regular food intake while trying to increase fruit and vegetable intake among children and adolescents.
\end{abstract}

\section{Introduction}

Adequate fruit and vegetable intake are important from a public health perspective. Diets with a high amount of fruits and vegetables reduce the risk of cardiovascular, endocrine, and other nutritional diseases [1], [2], [3]. Eating enough fruits and vegetables is especially important in adolescence. First, during this period, the body grows rapidly, requiring a lot of nutrients that can be provided by fruits and vegetables [4], [5], [6]. Second, food habits formed in childhood and adolescence tend to pass into adulthood [7], [8]. There are numerous determinants of fruit and vegetable intake among children and adolescents [9]. One of the insufficiently studied factors is the influence of the frequency of food intake. Sjöberg et al. found significantly higher consumption of both fruits and vegetables among 15-year-old Swedish girls with a regular meal intake. The analysis showed that girls who omitted breakfast and lunch at least once a week had a less healthy food choice than those who ate breakfast and lunch. Those who omitted meals had less fruit and vegetables and more white bread, soft drinks, and sweets. An analysis for boys was not performed [10].

There is considerable potential for stimulating fruit and vegetable intake since food habits in adolescence are often less consolidated than in adulthood [11]. Similarly, the study by Siega-Riz et al. among American adolescents aged 11-15 years showed that the number of fruit and vegetable servings was higher among adolescents with frequent meals compared with adolescents with less frequent meals [12]. Melnik et al. showed that American $2^{\text {nd }}$ - and $5^{\text {th }}$-grade students who omitted at least one main meal per day consumed fewer fruit and vegetable servings than those who did not omit meals. The association did not change by age. The tests were controlled by gender [13]. However, the study conducted by NeumarkSztainer et al. among 3957 American adolescents (the mean age of 14.9 years) did not reveal any correlation between the frequency of food intake and the consumption of fruits and vegetables [14]. Similarly, in the study by Cullen et al. among 10-year-old AfricanAmerican girls, no association was observed between the frequency of food intake and the consumption of fruits and vegetables [15], [16], [17]. 
In the Norwegian study among 13-15 years old, Lien et al. built a food count combining the weekly frequency of eating breakfast, lunch, and dinner. They found that a higher food score was associated with a higher fruit and vegetable intake (combined measure) [18]. Conducting epidemiological studies to identify the leading factors in the lifestyle of children and adolescents currently corresponds to the basic development directions of preventive medicine. In 43 European and North American countries, studies were conducted according to the methodology of the World Health Organization (WHO) to explore the health behavior in school-aged children (HBSC) [19], [20], [21].

The HBSC is the WHO international study aimed at analyzing various health behavioral factors of school-age children. It also includes a special study to assess the behavioral factors of obesity and overweight of school-aged children [23], [24], [25].

As shown, literature is limited on the relationship between the frequency of food intake and the consumption of fruits and vegetables among children and adolescents and does not give final results. In addition, there is little evidence of the potentially modifying effect of gender and age. Our goal was to find out whether the frequency of breakfast intake is related to the consumption of fruits and vegetables among children and adolescents, and whether potential associations are different between boys and girls and between different age groups.

In this study, the consumption of fruits and vegetables as well as the frequency of breakfast intake was analyzed separately. We chose this approach because associations can vary depending on fruits and vegetables.

\section{Materials and Methods}

The study was conducted according to the WHO methodology to create harmonized systems for the epidemiological surveillance of the health behavior of school-aged children (HBSC). The HBSC methodology was used in accordance with the HBSC member in Kazakhstan, the National Center for Public Health of the Ministry of Health of the Republic of Kazakhstan. The study was conducted on the basis of secondary schools in the cities of Aktobe, Atyrau, Aktau, and Uralsk of Western Kazakhstan and involved $5^{\text {th }}$-, $7^{\text {th }}$-, and $9^{\text {th }}$-grade students. To carry out the study, the cluster method of school sampling was used. With the application of random sampling, schools were selected that could enter the epidemiological surveillance system.

\section{Data collection}

The research data were collected by the approval of the ethics committee at Marat Ospanov West Kazakhstan Medical University. Documentation was provided to inform children and adolescents about the purpose of the survey, as well as about the ways to ensure confidentiality and anonymity. In this regard, children involved in the survey were asked for the written consent from schools and city departments of public education of each of the studied cities of Western Kazakhstan since they did not come of age at the time of the survey. However, regardless of the availability of such consent, student participation was voluntary.

\section{Research location and sample}

To carry out the study, a simple random sample of state comprehensive schools of the cities of Aktobe, Atyrau, Aktau, and Uralsk was used. In each sample school, the age groups of schoolchildren of 11,13 , and 15 years were selected: Aktobe $-n=376$, Aktau $-n=$ 367 , Atyrau $-n=369$, and Uralsk $-n=370$.

The cluster method of school sampling was used, where the school is the cluster or the basic unit of sampling. At the first stage, an analysis of the number of schools in the cities of Aktobe, Aktau, Atyrau, and Uralsk was carried out according to the following criteria: Location, form of ownership, completeness, etc. The choice of schools to be studied using random sampling was determined as follows: The sample was taken from schools that could be part of the epidemiological surveillance system; the requirements for the school state, includes medical personnel and a canteen.

\section{Research design}

The research design is a simultaneous crosssectional study.

\section{Results and Discussion}

The consumption of fruits and vegetables among children and adolescents was determined separately using the questionnaire with the main question: "How many times a week do you usually eat fruits or vegetables?" The answer categories included the following: "Never," "less than once," "once a week," "2-4 times a week," "5-6 times a week," "every time a day," and "every day more than once." Each dependent variable was identified, in which the low consumption of fruits and vegetables, respectively, was determined by eating fruits and vegetables $5-6$ days a week or less. To determine breakfast regularity, students were asked the following question: "How often do you have breakfast on weekdays and on weekends?" The 
answer categories included: On weekdays - "I never have breakfast," "one day," "two days," "three days," "four days," and "five days;" on weekends - "I never have breakfast," "I usually have breakfast on one of the weekends or on Saturday or Sunday," and "I usually have breakfast on both Saturday and Sunday."

The analysis by gender showed that no differences were found among boys or girls $(p=0.98630)$. The results of the study showed that $6.5 \%$ of boys and $6.0 \%$ of girls do not have breakfast daily on weekdays; $27.6 \%$ of boys and $27.1 \%$ of girls have breakfast on weekdays (Figure 1).

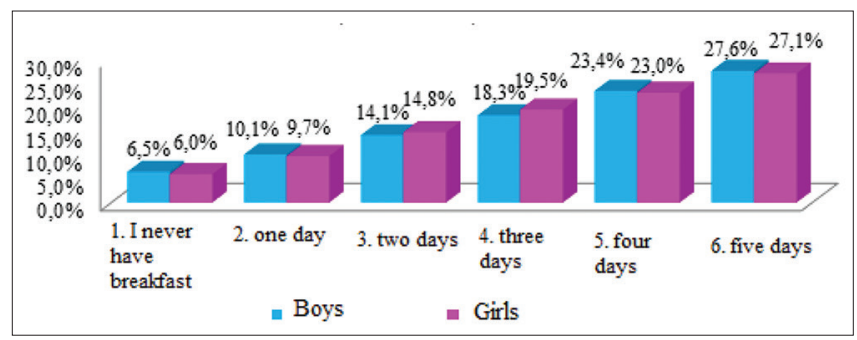

Figure 1: Breakfast frequency on weekdays by gender

According to Figure 2, $60.2 \%$ of boys and $51.3 \%$ of girls usually have breakfast on both Saturday and Sunday, $24.9 \%$ of boys and $32.2 \%$ of girls usually have breakfast on one of the weekends or on Saturday or Sunday, and $14.9 \%$ of boys and $16.5 \%$ of girls never have breakfast on weekends. The analysis by gender showed that there were some differences among boys and girls $(p=0.00003)$.

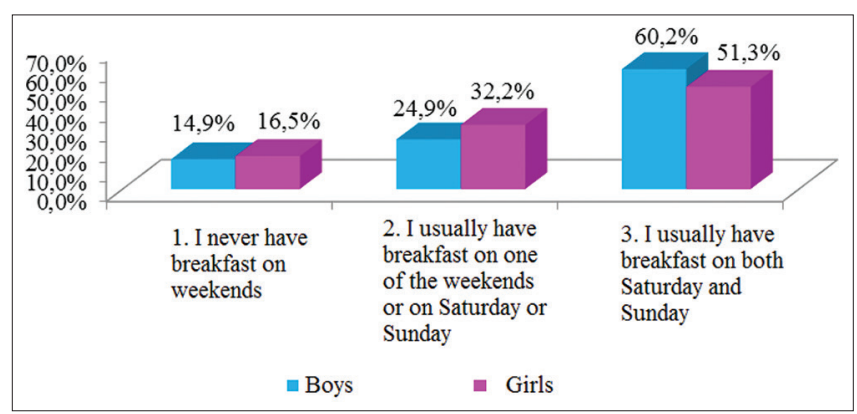

Figure 2: Breakfast frequency on weekends by gender

Based on the research results, the number of children omitting breakfast every day increases with age (Figure 3). In this regard, by the age of 15 years, $11.3 \%$ of schoolchildren never have breakfast on weekdays, while at the age of 11 , this figure is almost $8.8 \%$. The analysis of breakfast frequency on weekdays by age showed that no differences were found among boys or girls $(p=0.99954)$.

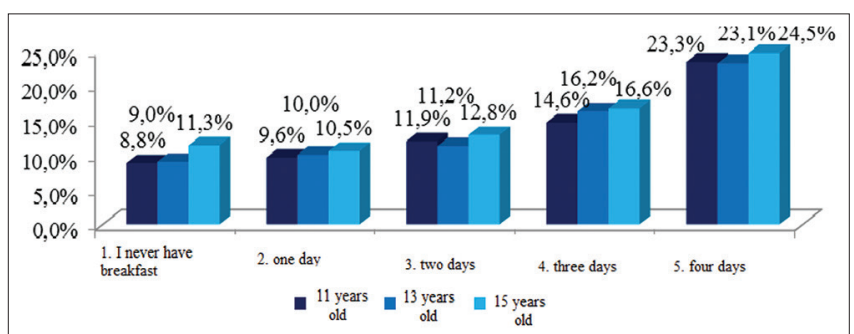

Figure 3: Breakfast frequency on weekdays by age
On weekends, 11-year-old children (54.0\%) usually have breakfast on both Saturday and Sunday. By the age of 15 years $(51.1 \%)$, the frequency of breakfast intake on weekends decreases. The analysis of breakfast frequency on weekends by age showed that there were no differences among boys or girls $(p=0.99479)$ (Figure 4).

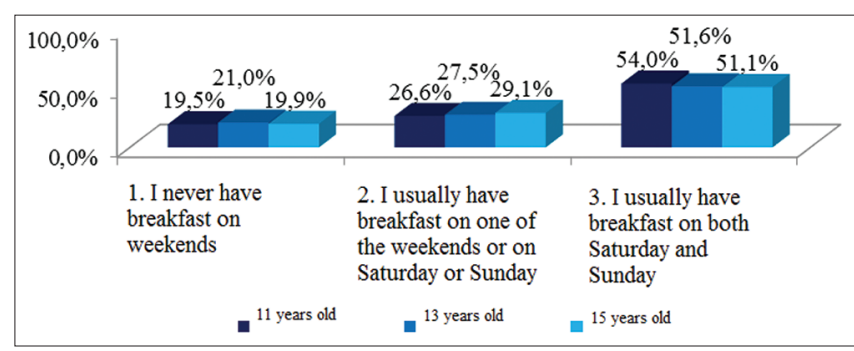

Figure 4: Breakfast frequency on weekends by age

The frequency of breakfast intake on weekdays by city is presented in Figure 5 . The most frequent breakfast intake, 5 times on weekdays, is observed among children from Uralsk (26.0\%), Aktobe (23.9\%), Atyrau (22.9\%), and Aktau (20.2\%). Pearson's Chisquare shows that there are some differences among cities $(p=0.00237)$ (Figure 5).

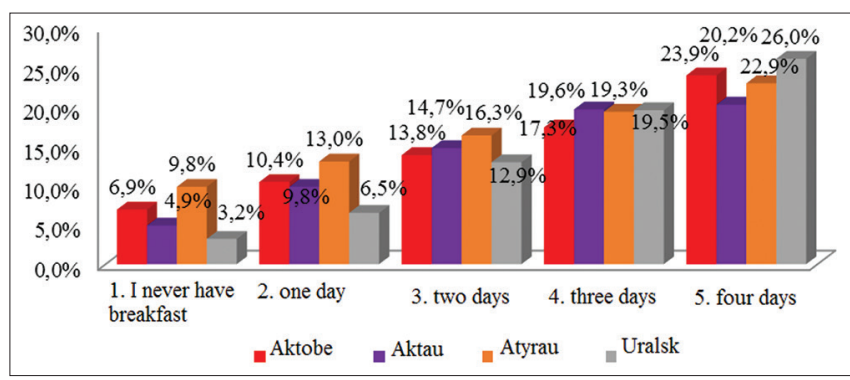

Figure 5: Breakfast frequency on weekdays by city

The frequency of breakfast intake on weekends in the cities of Aktobe, Aktau, Atyrau, and Uralsk is presented in Figure 6. Children usually have breakfast on both Saturday and Sunday. The higher indicators are mainly observed among children from Uralsk, compared with other cities. The analysis of breakfast frequency on weekends showed a strong relationship by city $(p=0.0000)$.

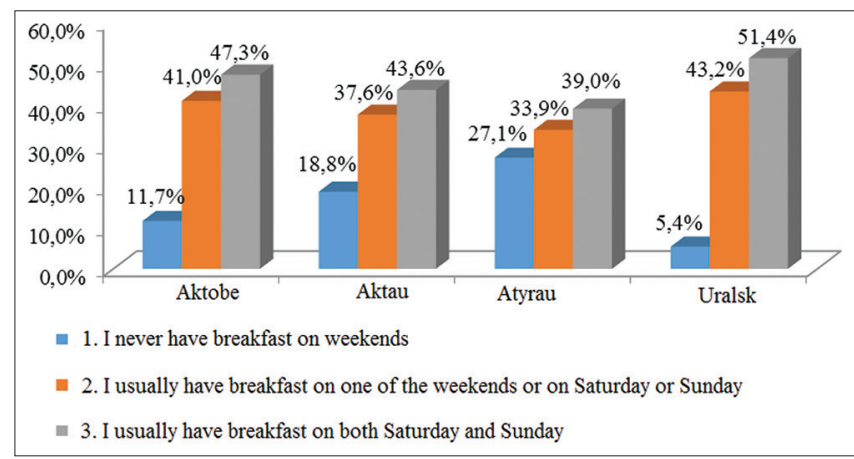

Figure 6: Breakfast frequency on weekends by city

The consumption of fruits and vegetables is analyzed separately using the food frequency 
questionnaire for several foods and drinks. The answer categories are the following: "Never," "Once a week," and "Several times a day." From a nutritional point of view, eating fruits and vegetables every day is preferable to eating fruits and vegetables less frequently. The direction of the associations was the same when changing the cut points. The difference was based both on a diet and on statistical data among the cities of Aktobe, Aktau, Atyrau, and Uralsk of Western Kazakhstan.

The consumption of fruits and vegetables has a direct effect on human health and contributes to the development of health in childhood (Figure 7). In the structure of consumed products, it was found that the majority of the respondents consume fruits and vegetables $2-4$ times a week (25.3\% of boys and $22.2 \%$ of girls). The irregular consumption of breakfast was associated with the low frequency of fruit consumption among the entire population group. In boys, the relationship between the irregular consumption of breakfast and the frequency of fruit consumption showed a statistically significant interaction with age $(p=0.48138)$.

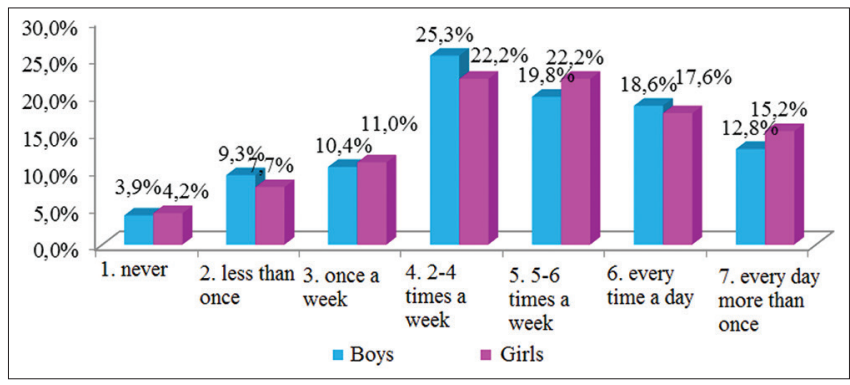

Figure 7: The frequency of fruit and vegetable consumption by gender

At the same time, the rate of vegetable consumption decreases with age. Among 11-year-olds, only $22.8 \%$ consume vegetables $2-4$ times a week, while by the age of 15 years, this indicator amounted to $29.3 \%$. The analysis of the frequency of fruit and vegetable consumption showed no relationship by age $(p=0.99866)$ (Figure 8).

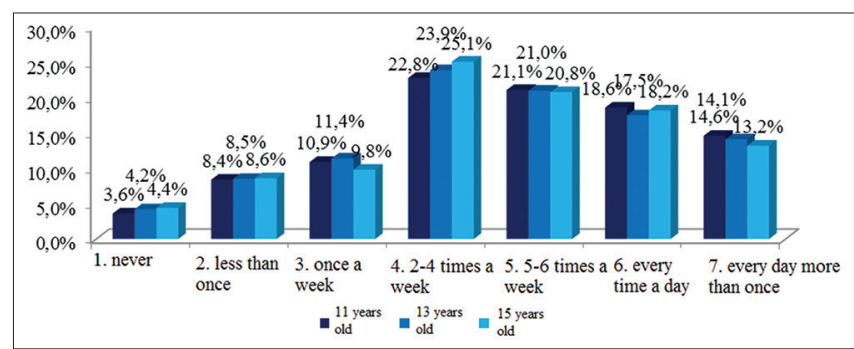

Figure 8: The frequency of fruit and vegetable consumption by age

In the context of the frequency of fruit and vegetable consumption by city, there is an increase in the ratio of children: Uralsk (31.9\%), Aktobe (23.9\%), Aktau (21.5\%), and Atyrau (17.6\%). The analysis of fruit and vegetable consumption by city showed a strong relationship ( $p=0.00000$ ) among the cities of Western Kazakhstan (Figure 9).

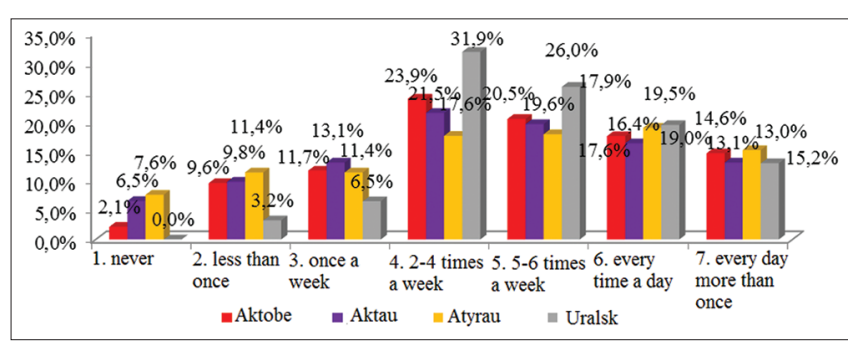

Figure 9: The frequency of fruit and vegetable consumption by city

Over the past two decades, the WHO has supported the development and synthesis of the evidence database to create measures to promote the health of children and adolescents by identifying the different determinants of their health. Much attention has been paid to the problems of health, development, and education of school-aged children and adolescents. Overweight and childhood obesity, which are spreading rapidly around the world, is becoming a major public health concern. These data are of great practical importance in terms of choosing the right time for interventions in children's health care and confirm the idea that it is necessary to continue to invest in children's health to consolidate the results achieved during interventions in early childhood.

In Kazakhstan, the frequency of functional disorders and chronic diseases among adolescents has increased in recent decades. The incidence trend is growing, being observed in almost all classes with the exception of infectious diseases. There is a growing increase in diseases of the nervous and endocrine system, as well as nutritional and metabolism disorders. There is an increase in the number of children subject to regular medical check-ups by psychiatrists in connection with pathological changes due to the use of psychoactive substances. This necessitates the strengthening of the system of measures aimed at the effective impact of public health care to maintain the health of adolescents.

Studies in near and far abroad countries have shown that the nutrition of schoolchildren in different countries is also irrational, with the amount of breakfast intake and the percentage of breakfast consumption being very low. Living conditions, the social and economic security of the family, as well as the level of employment of fathers and mothers, also affect breakfast consumption by children.

\section{Conclusions}

According to the research results, the frequency of breakfast intake among children and adolescents is irregular in the considered cities. The characteristic of breakfast also showed that there is a large imbalance in breakfast consumption by children and adolescents. 
Children and adolescents rarely have breakfast on weekdays. The most positive dynamics are observed among children in Uralsk, while the lowest indicator is observed among children in the cities of Aktobe, Aktau, and Atyrau. The dynamics of breakfast consumption on weekends are better. The number of children who have breakfast on Saturday is 2-3 times higher than those who have breakfast on weekdays.

The results showed that the irregular consumption of breakfast was associated with the low consumption of fruits and vegetables among children and adolescents. The analysis identified a strong relationship between children and adolescents of both genders. The study also showed that it is important to use separate fruit and vegetable consumption indicators.

\section{References}

1. Riboli E, Norat T. Epidemiologic evidence of the protective effect of fruit and vegetables on cancer risk. Am J Clin Nutr. 2003;78(3 Suppl):559S-69S. https://doi.org/10.1093/ ajcn/78.3.559s

PMid:12936950

2. Reddy KS, Katan MB. Diet, nutrition and the prevention of hypertension and cardiovascular diseases. Public Health Nutr. 2004;7(1A):167-86. https://doi.org/10.1079/phn2003587 PMid:14972059

3. Steinmetz KA, Potter JD. Vegetables, fruit, and cancer prevention: A review. J Am Diet Assoc. 1996;96(10):1027-39. PMid:8841165

4. He FJ, Nowson CA, MacGregor GA. Fruit and vegetable consumption and stroke: Meta-analysis of cohort studies. Lancet. 2006;367(9507):320-6. https://doi.org/10.1016/ s0140-6736(06)68069-0

PMid: 16443039

5. Ness AR, Powles JW. Fruit and vegetables, and cardiovascular disease: A review. Int J Epidemiol. 1997;26(1):1-13. PMid:9126498

6. Story M, Alton I. Adolescent nutrition: Current trends and critical issues. Top Clin Nutr. 1996;11:56-69. https://doi. org/10.1097/00008486-199606000-00008

7. Kelder SH, Perry CL, Klepp KI, Lytle LL. Longitudinal tracking of adolescent smoking, physical activity, and food choice behaviors. Am J Public Health. 1994;84(7):1121-6. https://doi. org/10.2105/ajph.84.7.1121 PMid:8017536

8. Lien N, Lytle LA, Klepp KI. Stability in consumption of fruit, vegetables, and sugary foods in a cohort from age 14 to age 21. Prev Med. 2001;33(3):217-26. https://doi.org/10.1006/ pmed.2001.0874

PMid:11522162

9. Rasmussen M, Krølner R, Klepp KI, Lytle L, Brug J, Bere E. Determinants of fruit and vegetable consumption among children and adolescents: A review of the literature. Part I: Quantitative studies. Int J Behav Nutr Phys Act. 2006;3:22. https://doi.org/10.1186/1479-5868-8-112

PMid:16904006

10. Sjöberg A, Hallberg L, Höglund D, Hulthén L. Meal pattern, food choice, nutrient intake and lifestyle factors in The Göteborg adolescence study. Eur J Clin Nutr. 2003;57(12):1569-78. https://doi.org/10.1038/sj.ejcn.1601726

PMid:14647222

11. Birch LL. Development of food acceptance patterns. Dev Psychol. 1990;26:515-9.

12. Siega-Riz AM, Carson T, Popkin B. Three squares or mostly snacks--what do teens really eat? A sociodemographic study of meal patterns. J Adolesc Health. 1998;22(1):29-36. https://doi. org/10.1016/s1054-139x(97)00125-0

PMid:9436064

13. Melnik TA, Rhoades SJ, Wales KR, Cowell C, Wolfe WS. Food consumption patterns of elementary schoolchildren in New York City. J Am Diet Assoc. 1998;98:159-64. https://doi.org/10.1016/ s0002-8223(98)00040-6

PMid: 12515416

14. Neumark-Sztainer D, Wall M, Perry C, Story M. Correlates of fruit and vegetable intake among adolescents. Findings from project EAT. Prev Med. 2003;37(33):198-208. https://doi. org/10.1016/s0091-7435(03)00114-2

PMid:12914825

15. Cullen KW, Baranowski T, Klesges LM, Watson K, Sherwood NE, Story $\mathrm{M}$, et al. Anthropometric, parental, and psychosocial correlates of dietary intake of African-American girls. Obes Res. 2004;12(S9):20S-31S. https://doi.org/10.1038/oby.2004.265 PMid:15489464

16. Lien N, Jacobs DR, Klepp KI. Exploring predictors of eating behaviour among adolescents by gender and socio-economic status. Public Health Nutr. 2002;5(5):671-81. https://doi. org/10.1079/phn2002334

PMid:12372162

17. Currie C, Nic GS, Godeau E. The health behaviour in schoolaged children: WHO collaborative cross-national (HBSC) study: Origins, concept, history and development 1982-2008. Int J Public Health. 2009;54(Suppl 2):131-9. https://doi.org/10.1007/ s00038-009-5404-x

PMid:19639260

18. Roberts C, Freeman J, Samdal O, Schnohr CW, De Looze M, Gabhainn SN, et al. The health behaviour in school-aged children (HBSC) study: Methodological developments and current tensions. Int J Public Health. 2009;54(Suppl 2):140-50. https://doi.org/10.1007/s00038-009-5405-9 PMid:19639259

19. Boyce $W$, Torsheim $T$, Currie $C$. The family affluence scale as a measure of national wealth: Validation of an adolescent selfreport measure. Soc Indic Res. 2006;78:473-87. https://doi. org/10.1007/s11205-005-1607-6

20. Erhart M, Ottova V, GasparT, JericekH, Schnohr C, Alikasifoglu M, et al. Measuring mental health and well-being of school-children in 15 European countries using the KIDSCREEN-10 Index. Int $J$ Public Health. 2009;54(Suppl 2):160-6. https://doi.org/10.1007/ s00038-009-5407-7

PMid: 19652910

21. Hetland J, Torsheim T, Aarø LE. Subjective health complaints in adolescence: Dimensional structure and variation across gender and age. Scand J Public Health. 2002;30:223-30. https://doi.org/10.1177/140349480203000309 PMid:12227979

22. Schnohr C, Kreiner S, Due E, Currie C, Boyce W, Diderichsen F. Differential item functioning of a family affluence scale: Validation study on data from HBSC 2001/02. Soc Indic Res. 2008;89:79-95. https://doi.org/10.1007/s11205-007-9221-4

23. Haugland S, Wold B. Subjective health complaints in adolescence reliability and validity of survey methods. J Adolesc. 2001;24(5):611-24. https://doi.org/10.1006/jado.2000.0393 
PMid:11676508

24. Molcho MI, Gabhainn SN, Kelleher CC. Assessing the use of the family affluence scale (FAS) among Irish schoolchildren. Ir Med J. 2007;100(Suppl 8):37-9.

PMid: 17955700
25. Haugland S, Wold B, Stevenson J, Aaroe LE, Woynarowska B. Subjective health complaints in adolescence. A cross-national comparison of prevalence and dimensionality. Eur $\mathrm{J}$ Public Health. 2001;11(1):4-10. https://doi.org/10.1093/eurpub/11.1.4 PMid:11276570 